\title{
DESEMPENHO DAS EXPORTAÇÕES BRASILEIRAS DE CELULOSE ${ }^{1}$
}

\author{
Sebastião Renato Valverde ${ }^{2}$, Naisy Silva Soares ${ }^{3}$ e Márcio Lopes da Silva²
}

\begin{abstract}
RESUMO - Este estudo objetivou de analisar o desempenho das exportações brasileiras de celulose, de 1993 a 2002, pelo método de Constant-Market-Share (CMS). Foi analisado o desempenho das exportações do Brasil, Canadá, EUA, Suécia e Finlândia, cujos resultados obtidos pela aplicação do método evidenciaram que o crescimento das exportações de celulose do Brasil e de seus principais concorrentes no mercado internacional foi explicado, principalmente, pelo crescimento do comércio mundial. O Brasil apresentou o maior efeito competitividade no ranking das exportações, seguido da Finlândia, já os demais países tiveram queda desse efeito. $\mathrm{O}$ crescimento da renda nos mercados compradores de celulose do Canadá, EUA e Suécia foi fator determinante do crescimento das exportações de celulose desses países. O contrário ocorreu com a renda dos países de destino das exportações brasileiras e finlandesas. A projeção das exportações de celulose indicou que, em 2035, o Brasil será o maior exportador de celulose em termos de valor exportado, mantidas as taxas de crescimento das exportações.
\end{abstract}

Palavras-chave: Constant-Market-Share, celulose e mercado internacional.

\section{PERFORMANCE OF THE BRAZILIAN WOOD PULP EXPORT}

\begin{abstract}
This study has the objective of analyzing the performance of the Brazilian wood pulp export, from 1993 to 2002, applying the constant-market-share method(CMS). The export performance of Brazil, Canada, USA, Sweden and Finland were evaluated. The growth of the Brazilian wood pulp export and of the main competitor in the international market was explained mainly by the growth of international trade. Brazil presented the highest competitiveness followed by Finland. The other countries presented decrease in competitiveness. The income growth of wood pulp buyer markets from Canada, USA and Sweden was a determinant for the growth of those country exports. The opposite happened with the income of countries of destination of the Brazilian and Finnish exports. The projection export indicated that in 2035 Brazil will be the major wood pulp exporter, in terms of export value, if the taxes of exports growth are maintained.
\end{abstract}

Keywords: Constant-Market-Share, wood pulp and international market.

\section{INTRODUÇÃO}

Desde 1950 o setor de papel e celulose vem-se desenvolvendo no Brasil. Naquela época, a indústria brasileira supria apenas $28,5 \%$ do consumo nacional, dadas as dificuldades para produção de celulose, pois a matéria-prima tradicional (Araucária Angustifólia ou pinheiro do paraná) só era encontrada em quantidades suficientes em regiões distantes dos centros produtores de papel e celulose. O eucalipto, considerado matéria- prima de qualidade inferior, teve a partir do fim de 1950 o desenvolvimento de uma tecnologia específica para sua utilização. Com isso, na década de 1960 o Brasil passou a produzir papel com $100 \%$ de celulose de eucalipto, e a produção de celulose de fibra curta superou à de fibra longa (GOMIDE, 1988). Na década seguinte, a política de incentivos fiscais ao reflorestamento, a atuação do Conselho de Desenvolvimento Industrial (CDI) e os investimentos com participação do Banco Nacional de Desenvolvimento Econômico (BNDE, hoje

\footnotetext{
${ }^{1}$ Recebido em 02.05.06 e aceito para publicação em 15.10.2006.

${ }^{2}$ Departamento de Engenharia Florestal da Universidade Federal de Viçosa, 36570-000 Viçosa-MG. E-mail: <valverde@ ufv.br>.

${ }^{3}$ Programa de Pós-Graduação em Ciência Florestal da UFV. E-mail: <naisysilva@ yahoo.com.br>.
} 
BNDES) contribuíram para a expansão da produção de celulose no Brasil (REZENDE e NEVES, 1988). Em 2003, o país foi o sexto maior produtor de celulose do mundo, com 7.436.000 toneladas (FAO, 2005).

O setor brasileiro de papel e celulose tem sido importante para o desenvolvimento do Brasil, pela geração de renda, emprego, tributos e divisas, com cerca de 220 empresas operando no setor, gerando 100 mil empregos diretos e indiretos nas indústrias e nas florestas e pagamento de R $\$ 1,7$ bilhão de impostos (BRACELPA, 2004).

As vendas de papel e celulose para o exterior representam cerca de $4 \%$ das exportações nacionais, com saldo comercial de US\$ 556 milhões, no início da década de 1990, e US\$2,5 bilhões em 2003 (BRASIL, 2004; BRACELPA, 2004). Essas exportações se concentravam basicamente em celulose de fibra curta derivada da madeira de eucalipto, com mais de $90 \%$ do total. Em 2003, os maiores compradores da celulose brasileira foram Europa (41\%), Ásia e Oceania (31,9\%), América do Norte $(25,4 \%)$, América Latina $(0,8 \%)$ e África (0,6\%) (BRACELPA, 2003).

As empresas brasileiras de celulose são competitivas mesmo com infra-estrutura inadequada de serviços sociais, transporte e telecomunicação, financiamento com taxas de juros elevada, alto custo de depreciação etc. Isso se deve à alta produtividade dos reflorestamentos, em razão das condições climáticas favoráveis à atividade florestal no país, possibilitando ciclos de crescimento rápido e de alta qualidade e baixo custo de produção em relação aos outros países (PIZZOL e BACHA, 1998).

O desempenho das exportações de celulose dos maiores exportadores mundiais entre 1982 e 1991 teve crescimento determinado, principalmente, por fatores internos que afetam a competitividade e por fatores externos, como crescimento da renda nos mercados compradores de celulose e expansão do comércio mundial (MEDEIROS e FONTES, 1994).

A evolução dos preços e fluxos do mercado internacional de celulose, considerando-se os principais exportadores (Canadá, EUA, Suécia, Brasil e Finlândia) e importadores (EUA, Japão, Itália, Alemanha, França, Inglaterra e Bélgica), mostrou que a demanda pela celulose dos principais exportadores mundiais é inelástica com relação ao preço. Mudanças exógenas que estimularam o crescimento da demanda de celulose no Japão e na Europa beneficiaram todos os países exportadores. Aumentos na produção de celulose dos Estados Unidos promoveram as maiores quedas de preço no mercado internacional, afetando os fluxos de comércio. A taxação de celulose no mercado europeu foi prejudicial a todos os países exportadores. Aumentos na produção de celulose no Brasil, por enquanto, quase não tem afetado os fluxos e preços do comércio mundial (OLIVEIRA, 1995).

A oferta e demanda internas de celulose, no mercado brasileiro de celulose e de papel e papelão, são preçoinelásticas, e as demandas interna e de exportação são mais sensíveis às variações na renda que no preço (SILVA, 1996).

Nesse contexto, este trabalho objetivou estudar o desempenho das exportações brasileiras de celulose de 1993-2002, com o método de Constante-Market-Share (CMS), confrontar o desempenho da indústria brasileira de celulose com a de seus concorrentes e projetar as tendências de crescimento das exportações de celulose do Canadá, EUA, Suécia, Brasil e Finlândia e, assim, verificar as mudanças no ranking dos países exportadores.

\section{MATERIAL E MÉTODO}

\subsection{Referencial Teórico}

Tomou-se como referência o método de CMS freqüentemente utilizado em estudos sobre crescimento e desempenho das exportações (HORTA, 1983; GONÇALVES, 1987; HORTA et al., 1994; ALMEIDA, 1994; CARVALHO, 1997).

Aplicações do método CMS relacionados a produtos florestais podem ser encontradas nos trabalhos desenvolvidos por Castillo e Laarman (1984), Medeiros e Fontes (1994), Angelo (2000) e Noce et al. (2003).

O método de CMS permite decompor a taxa de crescimento das exportações nos seguintes efeitos:

-Efeito crescimento do comércio: aumento observado se as exportações do país em foco tiverem crescido à mesma taxa de crescimento do comércio mundial.

- Efeito composição da pauta: incremento verificado nas exportações devido à concentração da pauta em produtos que apresentaram taxas de crescimento mais elevadas que a taxa média de todos os produtos. 
- Efeito destino das exportações: mudança originada das exportações de mercadorias para mercados mais ou menos dinâmicos.

- Efeito competitividade: alterações nas exportações devido a ganhos ou perdas de competitividade decorrentes de variações nos preços relativos, melhoria nas condições de financiamento e na eficiência do marketing ou da existência de taxas diferenciadas de inflação entre os países etc.

O efeito do crescimento do comercio mundial e a composição da pauta refletem a influência de fatores externos no desempenho das exportações. Já o efeito destino das exportações e a competitividade estão relacionados com fatores internos.

Se o efeito competitividade for negativo, isso significa que o país deixou de manter sua participação no comércio internacional e que os custos de produção do país está aumentando em proporção maior que os dos seus competidores e vice-versa. $\mathrm{O}$ efeito destino das exportações positivo indica que, no período analisado, o país em foco está exportando para mercados mais dinâmicos e vice-versa.

Análises baseadas no método CMS permitem avaliar a contribuição porcentual de cada efeito para explicar o crescimento ou queda das exportações. Assim, os resultados podem indicar alternativas de atuação e sinalizar caminhos de distribuição das exportações de modo a perseguir market-share de maior dinamismo. Mesmo o método tendo um caráter retrospectivo, existe a possibilidade de se fazer inferência sobre a direção das exportações para mercados mais dinâmicos e sobre a concentração em mercadorias com perspectivas mais dinâmicas, sob a pressuposição de continuidade das tendências observadas.

\subsection{Referencial Analítico}

\subsubsection{Projeção das exportações}

As projeções do valor exportado de celulose pelo Canadá, EUA, Suécia, Brasil e Finlândia foram calculadas com base na taxa média de crescimento anual, considerando-se o período de 1989 a 2002. A equação utilizada para cálculo foi a seguinte:

$$
T C=\left(\sum_{t=1}^{n-1} \frac{V E_{t}}{V E_{t-1}} / n-1\right)-1
$$

em que TC = taxa média de crescimento anual do valor exportado; $\mathrm{VE}_{\mathrm{t}}=$ valor das exportações no ano $\mathrm{t} ; \mathrm{VE}_{\mathrm{t}-1}=$ valor das exportações no ano $\mathrm{t}-1 ; \mathrm{e} \mathrm{n}=$ número de observações.

\subsubsection{O método CMS}

O método de CMS utiliza a seguinte equação:

$$
\sum_{j}\left(V_{j}^{\prime}-V_{j}\right)=\left(r V_{j}\right)+\sum_{j}\left(r_{j}-r\right) V_{j}+\sum\left(V_{j}^{\prime}-V_{j}-r_{j} V_{j}\right)
$$

em que $V^{\prime}{ }_{j}-V_{j}=$ crescimento efetivo do valor das exportações de celulose do país em foco para o mercado $j ; V_{j}=(p * q)=$ valor das exportações de celulose do país em foco para o mercado $\mathrm{j}$, no período $1 ; \mathrm{V}$, $=\left(p^{\prime} * q\right)=$ valor das exportações de celulose do país em foco para o mercado $\mathrm{j}$, no período 2 , sendo, $\mathrm{p}=$ preço das exportações de celulose do país em foco, no período 1 , em US\$/toneladas; p' = preço das exportações de celulose do país em foco, no período 2 , em US\$/toneladas; $\mathrm{q}_{\mathrm{j}}=$ quantidade de celulose exportada do país em foco ao mercado j, no período 1, em milhões de toneladas; $\mathrm{q}_{\mathrm{j}}=$ quantidade de celulose exportada do país em foco ao mercado j, no período 2 , em milhões de toneladas; $\mathrm{r}_{\mathrm{j}}=\left[\left(\mathrm{Xm}^{\prime}{ }_{\mathrm{j}} / \mathrm{Xm}_{\mathrm{j}}\right)-1\right] \rightarrow$ taxa de crescimento porcentual do valor das exportações mundiais de celulose para o mercado $\mathrm{j}$, entre os períodos 1 e 2 ; e r $=\left[\left(\mathrm{Xm}^{\prime} / \mathrm{Xm}\right)-1\right] \rightarrow$ taxa de crescimento porcentual do valor das exportações mundiais de celulose, entre os períodos 1 e 2, em que, $\mathrm{Xm}_{\mathrm{j}}=$ valor das exportações mundiais de celulose para o mercado j, no período 1, excluídas as exportações do país em foco; $\mathrm{Xm}_{\mathrm{j}}{ }_{\mathrm{j}}=$ valor das exportações mundiais de celulose para o mercado j, no período 2, excluídas as exportações do país em foco; $\mathrm{Xm}=$ valor das exportações mundiais de celulose no período 1; e $\mathrm{Xm}^{\prime}$ = valor das exportações mundiais de celulose no período 2 .

Os efeitos são assim determinados:

(1) Efeito crescimento do comércio mundial de celulose $=\sum_{j=1}^{n} r V_{j}$

(2) Efeito destino das exportações $=\sum_{j=1}^{n} r_{j} V_{j}-\sum_{j=1}^{n} r V_{j}$

(3) Efeito competitividade $=\sum_{j=1}^{n} V_{j}^{\prime}-\sum_{j=1}^{n} V_{j}-\sum_{j=1}^{n} r_{j} V_{j}$

Os mercados consumidores considerados para análise referem-se aos maiores importadores de celulose do Brasil em 2003 (EUA, Japão, Alemanha, China, Itália,

R. Árvore, Viçosa-MG, v.30, n.6, p.1017-1023, 2006 
França, R. U. e Bélgica) e o resto do mundo, que representa os demais países. Assim, o valor de n é igual a 9 .

\subsection{Fonte de dados}

Os dados sobre a quantidade produzida de celulose foram obtidos no site: $<$ http//:www.bracelpa.org.br>. Valor das exportações e quantidade exportada foram obtidos no site: <http//:www.fao.org >.

O período considerado para análise com base no método CMS foi de 1993 a 2002, visando abranger uma série temporal que reflita os resultados de abertura comercial global e os ajustes econômicos dos países em desenvolvimento ocorridos a partir da década de 1990. Não se trabalhou com datas mais recentes porque alguns dados não estavam disponíveis.

\section{RESULTADOS E DISCUSSÃO}

\subsection{Projeção das exportações}

Ao longo dos anos, o Brasil vem melhorando sua posição no ranking dos países exportadores de celulose, (Quadro 1).

A partir de 1980, o Brasil passou a ocupar posição de destaque como exportador de celulose devido à sua grande expansão nessa área a partir da década de 1970, proporcionada pelo I Programa Nacional de Papel e Celulose.

A evolução da exportação de celulose pelo Brasil e seus principais concorrentes, de 1961 a 2003, evidencia uma tendência geral crescente da quantidade exportada por esses países (Figura 1).

O Brasil apresentou a maior taxa média de crescimento anual das exportações de celulose, comparado com seus principais concorrentes, entre 1989 e 2002 (Quadro 2).

Mantidas essas taxas, em 2009 o Brasil ultrapassará a Suécia, em 2017 os EUA e em 2035 o Canadá, tornandose o maior exportador de celulose em valor.

De 1985 a 2002 não ocorreu nenhum projeto de implantação de nova indústria de celulose no Brasil, apenas expansão das existentes e aumento nas exportações. Projetos de expansão, como o da Aracruz Celulose em 2002, de 1,4 milhão para 2 milhões de toneladas de celulose por ano e a implantação da Veracel em 2005, que produzirá cerca de 900 mil toneladas por ano, além do potencial do país, mostram que esses saltos no ranking tendem a se antecipar. Isso indica que o Brasil galgue o topo do ranking mais cedo que o estimado.

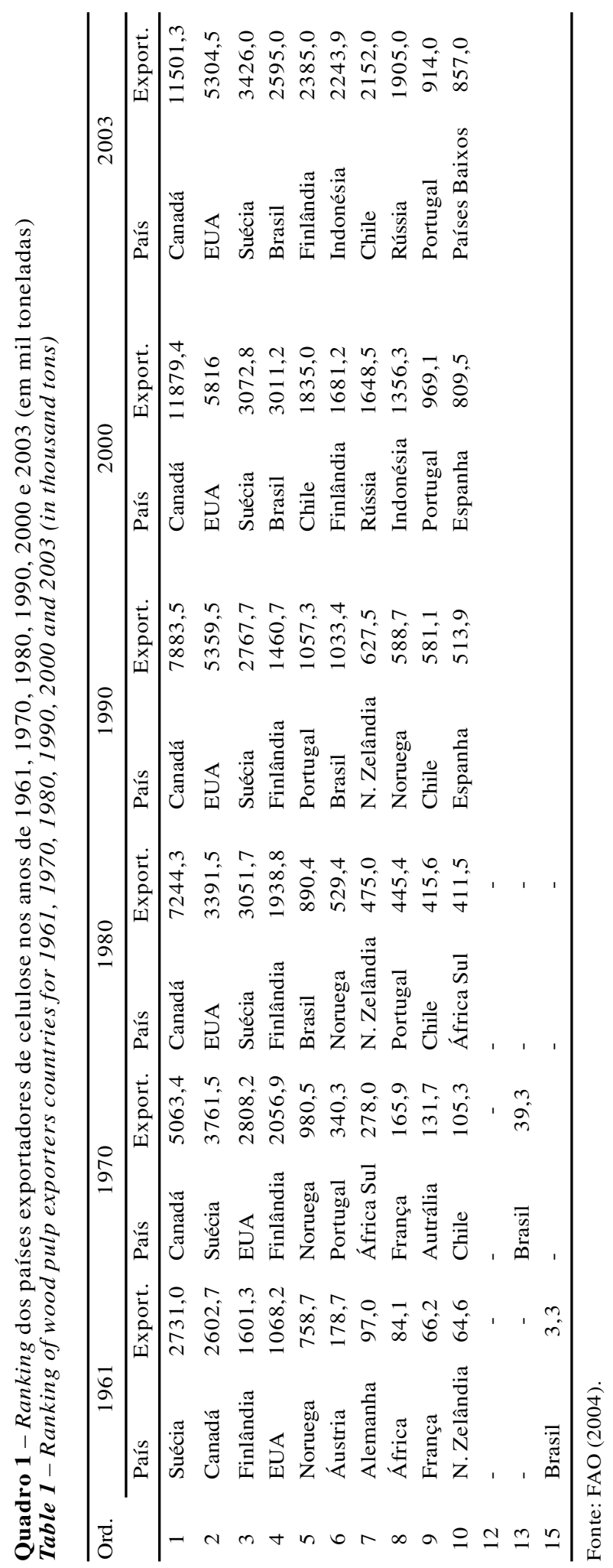




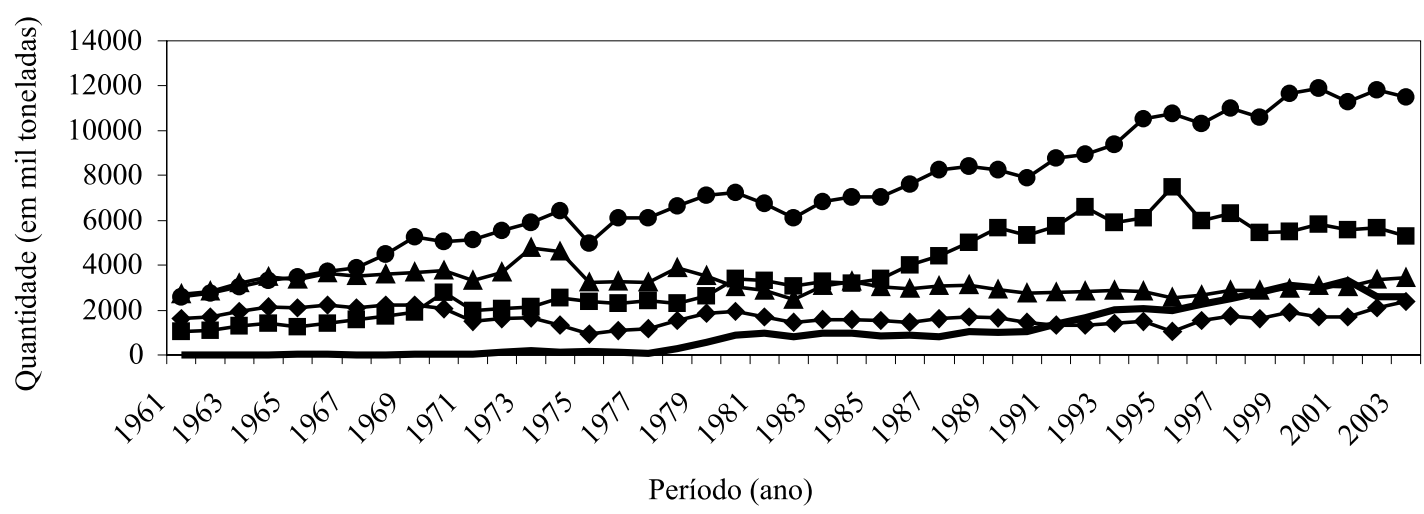

$$
\longrightarrow \text { Canadá } \longrightarrow \text { EUA — Brasil —- Suécia —-Finlândia }
$$

Fonte: FAO (2004).

Figura 1 - Evolução das exportações de celulose do Canadá, EUA, Brasil, Suécia e Finlândia, entre 1961 e 2003 (em mil toneladas).

Figure 1 -Evolution of wood pulp exports of Canada, USA, Brazil, Sweden and Finland, from 1961 to 2003 (in thousand tons).

Quadro 2 - Valor das exportações de celulose (em mil US\$) e taxa média de crescimento anual do valor exportado, de 1989 a 2002 (em \%)

Table 2 - Wood pulp export values (in thousand US\$) and average rates of annual growth of the exported value, from 1989 to 2002 (in \%)

\begin{tabular}{lcc}
\hline País & $\begin{array}{c}\text { Valor das } \\
\text { Exportações }\end{array}$ & $\begin{array}{c}\text { Taxa Média de Cresc. } \\
\text { Anual do Valor Exportado }\end{array}$ \\
\hline Canadá & $4.326,16$ & 1,6 \\
EUA & $2.612,23$ & 0,3 \\
Brasil & $1.146,31$ & 6,4 \\
Suécia & $1.457,56$ & 0,1 \\
Finlândia & 851,85 & $-1,1$ \\
\hline
\end{tabular}

Fonte: Resultados da pesquisa.

\subsection{Fontes de crescimento das exportações}

Os resultados do método de CMS avaliam os efeitos e a forma que cada um contribuiu para a evolução das exportações de celulose no período analisado, além de confrontar o desempenho da indústria brasileira de celulose com a de seus principais concorrentes (Quadro 3).

De 1993 a 2002, o crescimento do comércio mundial foi o principal fator explicativo da taxa de crescimento positiva das exportações de celulose do Brasil, Canadá, EUA, Suécia e Finlândia. Provavelmente esse crescimento esteja associado ao elevado acesso da população mundial aos meios de informação da rede universal de informações (internet) e da própria democratização do uso de computadores pessoais e impressoras que têm provocado aumento no consumo de papel. Isso explica $74,62 \%$ do crescimento das exportações de celulose do Brasil, 217,56\% do Canadá, 456,39\% dos EUA e $66,83 \%$ da Finlândia. A competitividade contribuiu com $47,86 \%$ para o crescimento das exportações de celulose do Brasil e 47,82\% para o crescimento das exportações de celulose da Finlândia. Isso significa que esses dois países estão mantendo sua participação no comércio internacional de celulose e que os custos de produção estão aumentando em proporção menor que a dos seus concorrentes. Assim, mantida constante a parcela das exportações brasileiras e finlandesas no mercado internacional, na ausência do efeito competitividade a taxa de crescimento das exportações de celulose desses dois países teria sido, respectivamente, de 47,86 e 47,82\% inferior à observada no período. Canadá, EUA e Suécia apresentaram efeito competitividade negativo, indicando queda na capacidade de competição desses países no mercado mundial de celulose, devido ao seu elevado custo de produção (Quadro 3).

O Brasil apresentou o maior efeito competitividade, com o rápido crescimento das plantações florestais e baixos custos de produção explicando a competitividade brasileira no mercado internacional de celulose.

O efeito destino das exportações atuou em sentido contrário ao crescimento das exportações de celulose do Brasil e da Finlândia. Na ausência desse efeito, as exportações brasileiras e finlandesas teriam sido, respectivamente, de 22,48 e 14,66\% maiores. No Canadá, EUA e Suécia, o efeito destino das exportações contribuiu, respectivamente, com 50,32\%, 440,79\% e 6,11\% para o crescimento das exportações.

R. Árvore, Viçosa-MG, v.30, n.6, p.1017-1023, 2006 
Quadro 3 - Fontes de crescimento das exportações de celulose do Brasil e de seus principais concorrentes no mercado internacional, no período de 1993 a 2002 , em \%

Table 3 - Sources of exports growth of Brazil's wood pulp and its main competitor in the international market, for the period from 1993 to 2002 , in \%

\begin{tabular}{lccccc}
\hline Itens & \multicolumn{3}{c}{ Mercados } \\
\cline { 2 - 5 } & Brasil & Canadá & EUA & Suécia & Finlândia \\
\hline Taxa de cresc. das exportações & 59,47 & 20,40 & 9,72 & 31,97 & 66,39 \\
Fontes de crescimento & & & & \\
Crescimento do comércio mundial & 74,62 & 217,56 & 456,39 & 138,81 & 66,83 \\
Destino das exportações & $-22,48$ & 50,32 & 440,79 & 6,11 & $-14,66$ \\
Competitividade & 47,86 & $-167,88$ & $-797,19$ & $-44,93$ & 47,82 \\
\hline
\end{tabular}

Fonte: Resultados da pesquisa.

\section{CONCLUSÃO}

A projeção das exportações indicaram que o Brasil apresentou a maior taxa de crescimento e, em breve, poderá ser o maior exportador de celulose em termos de valor exportado.

A análise das fontes de crescimento das exportações apontou que o Brasil e a Finlândia estariam ganhando competitividade no comércio internacional de celulose, enquanto o Canadá, EUA e Suécia estariam perdendo. Os EUA apresentaram o pior desempenho nas exportações de celulose, e sua participação no comércio mundial caiu sensivelmente, como evidencia o efeito competitividade de $-767,19 \%$ e a sua taxa de crescimento porcentual de apenas 9,72\%. O Brasil e a Finlândia estariam exportando para mercados menos dinâmicos, e as vendas externas do Canadá, EUA e Suécia estariam se direcionando para mercados que estão crescendo a taxas superiores à mundial.

\section{REFERÊNCIAS BIBLIOGRÁFICAS}

ALMEIDA, G. B. Indicadores de competitividade para a indústria brasileira no período 1974/91. Perspectiva da Economia Brasileira, v. 1, p. 359-396, 1994.

ANGELO, H.; BERGER, R.; HOSOKAWA, R. T. C. L. Competitividade da madeira tropical brasileira no mercado internacional. Revista Árvore, v. 24, n. 2, p. 123-126, 2000.

\section{ASSOCIAÇÃO BRASILEIRA DE CELULOSE E} PAPEL - BRACELPA. Números do setor. 2004. Disponível em: <http:// www.bracelpa.org.br>. Acesso em 04/06/2004.

R. Árvore, Viçosa-MG, v.30, n.6, p.1017-1023, 2006
ASSOCIAÇÃOBRASILEIRADECELULOSEEPAPEL - BRACELPA. Relatório anual. 2003. 28 p.

CARVALHO F. M. A. A dinâmica agroexportadora brasileira: mudança estrutural, vantagem comparativa e fontes de crescimento. Revista de Economia e Sociologia Rural, v. 35, n. 1, p. 9-44, 1997.

CARVALHO F. M. A. Método "constante market share”. In: SANTOS, M.L.; VIEIRA, W.C.

Métodos quantitativos em economia. Viçosa, MG: Universidade Federal de Viçosa, 2004. p. 225-241.

CASTILLO, M.; LAARMAN, J. G. A market-share model to assess price competitiveness of softwood lumber exports to Caribbean markets. Forest Science, n. 30, v. 4, p. 928-932, 1984.

CELULOSE \& PAPEL. Celulose papel: setor fecha 98 com resultados modestos. v. 15, n. 64, p. $14-17,1999$.

FOOD AND AGRICULTURE ORGANIZATION FAO. Disponível em: <http//:www.fao.org >. Acesso em: 23/09/2004.

GOMIDE, J. L. Situação atual e perspectivas futuras do setor de celulose e papel no Brasil. In: SIMPÓSIO BILATERALBRASIL-FINLÂNDIASOBRE ATUALIDADES FLORESTAIS, 1988, Curitiba. Anais... Curitiba: UFPR/IBDF, 1988. p. 296-302.

GONÇALVES, R. Competitividade internacional, vantagem comparativa e empresas multinacionais: o caso das exportações brasileiras de manufaturados. Pesquisa e Planejamento Econômico, v. 17, n. 2, p. 411-436,1987. 
HORTA, M. H. Fontes de crescimento das exportações brasileiras na década de 70 .

Pesquisa e Planejamento Econômico, v. 13 , n. 2, p. 507-542, 1983.

HORTA, M. H.; WADDINGTON, S; SOUZA, C. F. Fontes de crescimento das exportações brasileiras na década de 80. In: Perspectiva da

economia brasileira. Rio de Janeiro: IPEA, 1994. v 1, p. 231-246.

MEDEIROS, V. X.; FONTES, R. M. O. Competitividade das exportações brasileiras de celulose no mercado internacional. Revista de Economia e

Sociologia Rural, v. 32, n. 2, p. 105-121, 1994.

MINISTÉRIODODESENVOLVIMENTO,

INDÚSTRIA E COMÉRCIO - MDIC. Papel e

celulose. sd. Disponível em: $<\mathrm{http}: / /$

www.desenvolvimeto.gov.br/arquivo/sdp/proacao/

forcompetitividade/imprzonlivcon/

12papaleceluloseresumo.pdf >. Acesso em: 03/05/04.

NOCE, R. et al. Desempenho do Brasil nas exportações de madeira serrada. Revista Árvore, v. 27, n. 5, p. 695-700, 2003.
OLIVEIRA, A. D. Análise das possíveis mudanças comerciais e estruturais do mercado internacional de celulose. 1995. 131 f. Tese (Doutorado em Ciência Florestal) - Universidade Federal de Viçosa, Viçosa, MG, 1995.

PIZZOL, S. J. S.; B ACHA, C. J. C. Evolução, estrutura e desafios da indústria de celulose no Brasil. Preços Agrícolas. v. 12, n.137, p. 3-13, 1998.

REZENDE, J. L.; NEVES, A. R. Evolução e contribuição do setor florestal para a economia brasileira. In: SIMPÓSIO BILATERAL BRASILFINLÂNDIA SOBRE ATUALIDADES FLORESTAIS, 1988, Curitiba. Anais... Curitiba: UFPR/IBDF, 1988. p. 214-265.

SILVA, M. L. Análise econométrica do mercado brasileiro de celulose e de papel e papelão. 1996. $120 \mathrm{f}$. Tese (Doutorado em Ciência Florestal) - Universidade Federal de Viçosa, Viçosa, MG, 1996. 